\title{
As diversas formas do conhecimento: bases histórico-filosóficas da pesquisa em educação
}

Silvio Sánchez Gamboa ${ }^{1}$

\section{Resumo}

Visando contribuir para o debate sobre a qualidade da pesquisa educacional e procurar critérios epistemológicos que favoreçam essa qualidade, retomamos algumas bases históricas e filosóficas sobre as diversas formas do conhecimento. O artigo apresenta justificativas sobre a importância da literatura clássica para compreender a problemática atual da produção do conhecimento. Os critérios que, de acordo com a filosofia clássica grega, diferenciam os saberes, tais como, o opinativo, a razão mítica, a episteme e a filosofia, hoje continuam válidos para abordar os principais conflitos da pesquisa em educação, compreender os desafios da formação do pesquisador e definir a qualidade dessa pesquisa.

Palavras-chave: Pesquisa educacional; Filosofia Clássica; Epistemologia.

\section{Resumen}

Con el objetivo de contribuir con el debate sobre la calidad de la investigación educativa y con la búsqueda de criterios epistemológicos que favorezcan esta calidad, retomamos algunas bases históricas y filosóficas sobre las diversas formas de conocimiento. El artículo presenta las justificaciones sobre el valor de la literatura clásica para comprender la problemática actual de la producción del conocimiento. Los criterios que, de acuerdo con la filosofía clásica griega, diferencian los saberes, tales como, el opinativo, la razón mítica, la episteme y la filosofía, hoy continúan válidos para entender los principales conflictos de la investigación en educación, los retos de la formación del investigador e para definir la calidad de esa investigación.

Palabras clave: Investigación educativa; Filosofía Clásica; Epistemología.

\footnotetext{
${ }^{1}$ Professor titular da Faculdade de Educação da Unicamp, líder do Grupo de Estudos e Pesquisa em Filosofia da Educação PAIDEIA.
} 


\section{Introdução}

or ocasião das comemorações da fundação do grupo de estudos e
pesquisa em Filosofia da Educação PAIDEIA, da Faculdade de
Educação da Unicamp, além da excelente oportunidade de socializar algumas reflexões sobre as bases histórico-filosóficas da pesquisa em Educação, considero também importante o momento para resgatar critérios de rigor científico que ajudem a qualificar a produção da pesquisa, destacar seu compromisso com a compreensão da problemática da educação, bem como, com a transformação social.

A pesquisa em educação, particularmente a desenvolvida no lugar privilegiado do sistema de pós-graduação brasileiro, desde seus primórdios nos anos de 1970, vem sendo submetida a embates sobre suas características diferenciadas com relação aos critérios de rigor científico que, de uma ou outra forma, atentam contra sua qualidade e desvirtuam sua função social.

A produção da pesquisa científica foi proposta como um dos objetivos principais da pós-graduação stricto sensu (mestrado e doutorado), e da sua diferenciação com os cursos lato sensu (aperfeiçoamento e especialização). O Parecer 977/65, o Relatório do Grupo de Trabalho da Reforma Universitária - 1968 -, e o I Plano Nacional de Pós-Graduação - 1974 situam a produção científica como um instrumento para desenvolver a capacidade de pensar e criar, reservada aos mais aptos e necessária para o desenvolvimento do ensino superior; daí recorre o papel e a importância que se dá à dissertação e à tese para a obtenção dos graus de mestre e doutor, além da razão pela qual a pesquisa se constitui na pedra angular dos cursos de pósgraduação.

De acordo com esse ideário, a produção de dissertações e teses nos programas de pós-graduação stricto sensu é demarcada pelos critérios que regem o conhecimento científico. Entretanto, quando essa produção é avaliada, os indicadores apontam para profundas distâncias com relação ao rigor exigido para esse tipo de conhecimento. Nos balanços gerais sobre a produção brasileira em educação, já desde os anos de 1990, identificavam-se graves deficiências que se justificavam nas condições político-sociais 
desfavoráveis, na mesma natureza epistemologia da pesquisa educacional que se situa no campo fronteiriço do conhecimento científico, a prática educacional e variedade de critérios de avaliação, distantes dos parâmetros do rigor científico ${ }^{2}$.

Com relação à avaliação das pesquisas em educação, desde sua origem, nos anos de 1970, predomina uma miríade de formatos e tendências, "a dispersão e a variação temática, os cortes temáticos muito estreitos e fragmentários" (WARDE, 1993, p.51). Com relação às metodologias, predominam os estudos exploratórios tanto de caráter quantitativo como qualitativo, o que indica não só o despreparo para o domínio desse tipo de estudos, como para realizar diagnósticos de alto alcance sobre os problemas da educação.

Perante à necessidade de depurar o critério da avaliação da produção de acordo com a tradição científica e de aprimorar as exigências epistemológicas para buscar maiores níveis de qualidade dessa produção, propomos retomar as bases histórico-filosóficas que especificam o conhecimento científico.

$\mathrm{Na}$ conjuntura atual da cultura informatizada e da sociedade da informação, também o conhecimento em geral e, especificamente, o científico, é submetido a novos embates que sintomaticamente podemos exemplificar em dois termos de amplo "contágio" nas redes sociais: "pósverdade" e "uberalização do conhecimento, ou capitalismo cognitivo".

Esses termos revelam o contágio do predomínio das linguagens, discursos, versões, opiniões, boatos, com intensa carga subjetiva, sobre os fenômenos, os objetos, os fatos, a realidade ontológica e o conhecimento, bem como revelam a obscura fase da sociedade da informação, do império da opinião pública e do "capitalismo cognitivo". Esse ambiente do contexto social e político, não apenas contamina a pesquisa em educação, como também se apresenta como um dos grandes desafios da problemática atual da educação.

\footnotetext{
${ }^{2}$ Dentre os balanços da produção destaca-se o documento da ANPED (1993).
} 
O termo "pós-verdade ${ }^{3}$ foi consagrado em 2016 pelo Dicionário Oxford, ano em que a sociedade preferiu os boatos aos fatos. Segundo a revista The Economist, que popularizou o termo, o mundo teria entrado na era política de "pós-verdade", citando como exemplo, os britânicos que ignoraram os alertas sobre o "Brexit" e votaram pela separação da Comunidade Europeia, os americanos que desprezaram as graves advertências sobre Donald Trump, mesmo assim o elegeram, os colombianos que votaram contra os acordos de paz do governo com as FARC. Nessa oportunidade, as igrejas convenceram boa parte dos eleitores de que os acordos estimulariam a homossexualidade das crianças, quando o tratado apenas propunha a equidade de gênero, "para garantir que mulheres e homens participem e se beneficiem em pé de igualdade da implementação desse acordo", mas o boato de que "O anticristo está na Colômbia", "viralizado" por um pastor nas redes sociais, se tornou a "verdade" sobre a temível “ideologia de gênero". Outro exemplo aconteceu no Brasil, o afastamento da presidenta Dilma Rousseff, que não cometeu nenhum crime de responsabilidade, condição indispensável para o impeachment, foi deposta pelo "conjunto da obra". De acordo com a revista The Economist, a "pósverdade" disseminou-se pela internet e das redes sociais. "A fragmentação das fontes noticiosas criou um mundo atomizado, em que mentiras, rumores e fofocas se espalham com velocidade alarmante", diz a revista. "Mentiras compartilhadas online, em redes cujos integrantes confiam mais uns nos outros do que em qualquer órgão tradicional de imprensa, rapidamente ganham aparência de verdade" (VILLAS-BOAS, 2017, p.1).

A discussão sobre o problema da verdade é antiga, os clássicos gregos

\footnotetext{
${ }^{3}$ Segundo a definição dos dicionários Oxford, pós-verdade ('post-truth' em inglês) é um adjetivo que faz referência a "circunstâncias em que os fatos objetivos têm menos influência na formação de opinião pública do que os apelos emocionais e as opiniões pessoais". O termo, diz a Oxford, foi empregado pela primeira vez em 1992 pelo dramaturgo sérvio-americano Steve Tesich, em um ensaio para a revista The Nation. Em 2004, o escritor norte-americano Ralph Keyes colocou-o no título de seu livro The Post-Truth Era: Dishonesty and Deception in Contemporary Life. Mas quem mais contribuiu para a sua popularização mundial foi a revista The Economist, desde quando publicou, em setembro de 2016, o artigo "Arte da mentira". O uso da palavra pela imprensa mundial em 2016 cresceu $2.000 \%$ em relação ao ano anterior, principalmente na cobertura de fatos políticos. (Ver referência disponível em: https://noticias.uol.com.br/politica/ultimas-noticias/2016/12/31/por-que-pos-verdade-foi-apalavra-do-ano-e-o-que-ela-diz-sobre-2016.htm.)
} 
se depararam com a necessidade da adequação entre os fatos objetivos, a percepção humana através dos sentidos e a comunicação (logos) desses fatos, através das linguagens. Daí a importância da retomada desses conceitos e dessa lógica que relaciona os fatos e a comunicação deles, a relação entre a objetividade e a subjetividade.

O problema da verdade como construção história concreta, nem pode estar presa a um suposto realismo objetivo, nem a um suposto subjetivismo. A relação cognitiva é complexa e a adequação entre fatos fenômenos (objetivos), processos de percepção (empiria) e a construção (sempre subjetiva) de informações e a comunicação através da linguagem, sempre se dá em contextos sociais e culturais que determinam diversos critérios de verdade. A ideia de pós-verdade pode ser um modismo cibernético que esconde, ou ignora a problemática filosófica da verdade.

Já o termo "capitalismo cognitivo" ou "uberalização do conhecimento", reduz o conhecimento ao "efeito instrumental pragmático do conhecimento", que pretende transformar a mente humana num computador, e processa informações, segue comandos controlados pelas grandes redes internacionais, ao exemplo do Uber que localiza um consumidor. E ainda, na mesma hora, controla todas suas informações disponíveis, através de seus cadastros, e-mails e celulares ${ }^{4}$. Ao transformar donos de veículos em choferes eventuais sem nenhuma proteção, o Uber simboliza cada vez mais a ligação entre novas tecnologias e precarização do trabalho. "Se o Uber se mostra eficiente, é porque controla a fonte de produção dos dados: nossos telefones lhe dizem tudo o que precisa saber para planejar um itinerário." (Morozov, 2015$, p. 1$)^{5}$.

Segundo Ferreira (2017, p. 1), analisando a conjuntura atual da mídia brasileira, constata,

O País está hipnotizado pelo show diário de meganhagem midiática de

\footnotetext{
${ }^{4}$ Disponível em: https://mail.google.com/mail/ca/u/0/\#inbox/15b9b6107a0afa04 Acesso em 22/04/2017.

${ }^{5} \mathrm{O}$ grau de acumulação de capital, com base no trabalho precarizado dos choferes e no controle de uma rede de informações levou a empresa, que não possui quase nenhum ativo, a atingir um valor de US\$ 40 bilhões.
} 
colarinhos brancos sendo levados presos por cinematográficos policiais federais com suas reluzentes botas e armas negras. Porém, a passos lentos, mas seguros, no subterrâneo desse espetáculo de moralização nacional está ocorrendo uma revolução silenciosa que vai determinar o futuro das próximas gerações: reformas educacionais que estão impondo uma agenda secreta, a gestão de um novo projeto de nação [...]. Saem pedagogos, entram engenheiros e gestores. No lugar de valores como autonomia e conhecimento entram "disparos neuronais" e "sinapses" para formar futuros profissionais que não mais lidarão com conhecimentos, mas com "efeitos do conhecimento" das plataformas tecnológicas - a "uberização" da educação. Uberização" da educação: saem pedagogos e Construtivismo, entram gestores e neurociências.

Mas não só saem os pedagogos: saem os modelos educacionais tradicionais que propõem uma educação pela autonomia na construção do conhecimento e entram as neurociências aplicadas na educação - nas quais a atenção a "disparos neuronais" e "sinapses" fazem analogia da mente a um computador que assimila informação, processa e dá feedbacks. O indivíduo é transformado num nódulo da rede neuronal ou eletrônica. Ele não precisa ter o domínio de conhecimentos, ele precisa estar conectado a uma rede e "saber fazer" uma determinada função e se conectar a eventuais novas redes e novas funções.

Perante esses embates contra a validade do conhecimento e sua fundamentação lógica vale a pena recuperar a problemática do conhecimento, buscando nas origens históricas das diversas formas do conhecimento possíveis esclarecimentos. Nessa perspectiva, apresento a seguir: 1) a justificativa do recurso aos clássicos para compreender uma problemática atual, particularmente quando se trata da compreensão da pesquisa em educação; 2) as diversas formas do conhecimento segundo a filosofia clássica grega, o mito, o senso comum, a religião, a ciência e a filosofia e suas contribuições para a compreensão da problemática contemporânea da pesquisa em educação; 3) Os principais conflitos da pesquisa em educação; 4) os desafios da formação do pesquisador e finalmente, à guisa de 
conclusões, algumas sugestões para o debate.

\section{O sentido das referências clássicas}

Segundo Jaeger (2001), a formação do homem atual e a nossa própria formação têm a ver com o humanismo dos primeiros tempos. O humanismo é hoje mais candente e mais discutido do que nunca. É claro que a solução do problema do humanismo atual não pode resultar de uma investigação histórica, uma vez que a problemática abordada não trata dos gregos, mas de nós próprios.

No entanto, o conhecimento essencial da formação grega constitui um fundamento indispensável para todo o conhecimento ou intento de educação atual. Foi esta convicção a origem do meu interesse científico pelo problema e, consequentemente, a origem deste livro. (JAEGER 2001, p.11)

O mergulho na vasta cultura clássica que conecta o antigo com o contemporâneo revela as lutas pela produção social da humanidade quando vista na sua historicidade. Tal o sentido que tem o resgate da dimensão histórica do saber pedagógico. Por exemplo, revelações como as registradas por Manacorda sobre a escola pitagórica (séc. VI a. C) que diferencia os bens e valores não transmissíveis e os transmissíveis e entre estes últimos, os que são trocados (com perda deles) e partilháveis (sem perda). Seu princípio é que frente aos bens não-transmissíveis como a força, a saúde, a beleza, a coragem, ou transmissíveis, perdendo-os quem os transmite, como a propriedade, os cargos, existe um bem que se transmite sem perdê-lo: é a educação, a paideia (1989, p. 47). Tal princípio certamente continua sendo válido, quando se justifica o valor da educação no quadro comparativo dos bens sociais e se pretende definir a natureza da educação como a construção social do homem e como trabalho não material cujo produto (a própria produção do homem) não se separa do processo da produção (o ato de 
educar) ${ }^{6}$.

Outras das razões da presença da referência da filosofia clássica na compreensão dos problemas, que a realidade educacional coloca, está nas linhas de permanência que a mantém viva e atual. Uma delas é a sua radicalidade crítica. Nesse sentido, Suchodolski (1984) procura no confronto crítico das grandes visões do homem a caracterização das correntes pedagógicas que perpassam a história da educação. Ele considera que,

[...] penetrar no aspecto profundo do processo profundo do processo do desenvolvimento do pensamento pedagógico moderno e evidenciar as lutas crescentes que ocorrem entre o que se poderá designar a pedagogia da existência e a pedagogia da essência [...] encontra a controvérsia filosófica clássica da filosofia da essência e da filosofia da existência, controvérsia que remonta aos tempos mais recuados e que se mantém até nossos dias. Esta querela filosófica não respeita unicamente os problemas metafísicos abstratos, toca o próprio homem. (p.16).

Saviani (2008) também recorre à contribuição acumulada da filosofia, quando discute as atuais perspectivas da formação do educador. Ele destaca a concepção da "fase clássica" de Gramsci e sua importância na superação da polêmica entre as tendências pedagógicas:

Em lugar de alimentarmos as polêmicas entre as correntes pedagógicas, em especial entre as correntes ditas tradicionais e aquelas renovadas, cabe aceitar o convite para entrar na fase clássica, que é aquela em que já se deu uma depuração, ocorrendo a superação dos elementos da conjuntura polêmica com a recuperação de aquilo que tem caráter permanente porque resistiu aos embates do tempo (p.151).

No mesmo texto defende a história como lugar central no novo princípio educativo da escola de nosso tempo: uma escola unitária porque

\footnotetext{
${ }^{6} \mathrm{Na}$ relação pedagógica o educador transmite saberes ao educando, entretanto, não perde esse saber no ato de partilhar; pelo contrário, se esse ato for criativo e estimulador, o próprio educador se enriquece.
} 
guiada pelo mesmo princípio, o da radical historicidade do homem e organizada em torno do mesmo conteúdo, a própria história dos homens, identificada como o caminho comum para formar indivíduos plenamente desenvolvidos.

Uma vez ponderada a importância das referências da Filosofia clássica, com base na amostra de alguns autores, retomemos a contribuição da Filosofia grega na compreensão da controvérsia das diversas formas do conhecimento para compreender as atuais polêmicas sobre o trato dos saberes na formação e na prática pedagógica dos educadores e dos pesquisadores em educação.

2. As diversas formas do conhecimento na filosofia clássica grega

Organizo este item nos seguintes tópicos: 1) o contexto histórico social da origem do conflito das formas do conhecimento; 2) o conflito entre mito, religião (razão mítica: mythos) e o conhecimento científico (episteme); 3) o conflito entre senso comum (doxa) e ciência (episteme; 4) o conflito entre o conhecimento científico (episteme) e a filosofia (sofia); e, 5) a importância atual da Paideia Grega.

2.1. O contexto histórico-social da origem do conflito sobre as formas do conhecimento

Vernant (2002) relaciona as origens do pensamento helênico com as profundas mudanças na sociedade grega, que vinha sendo organizada desde a civilização micênica (séc. XII a.C.) com base no poder religioso da monarquia na figura do "Rei-divino". A religião e a mitologia da Grécia clássica arraigam-se muito diretamente [...] no passado micênico. Mas, quando no século XII o poder micênico desaba não é uma simples dinastia que sucumbe, é sim um tipo de realeza que é para sempre destruída, é toda uma forma de vida, centralizada em torno do palácio, que é definitivamente abolida, é o "Rei divino" que desaparece do horizonte grego. Tal desaparecimento prepara uma dupla e sólida inovação: a instituição da cidade e o nascimento de um pensamento racional (cf. 2002, p. 9). Segundo o mesmo 
Vernant,

Se quisermos proceder ao registro de nascimento dessa razão grega, seguir a via por onde ela pode livrar-se de uma mentalidade religiosa, indicar o que ela deve ao mito e como o ultrapassou, devemos comparar, confrontar com o background micênico essa viragem do século VIII ao século VII em que a Grécia toma um novo rumo e explora as vias que lhe são próprias [...] lança os fundamentos do regime da Pólis e assegura por essa laicização do pensamento político o advento da filosofia (p.11).

O advento da Polis (entre os séculos VIII e VII) constitui um acontecimento decisivo. O que implica o sistema da polis é primeiramente uma extraordinária preeminência da palavra sobre todos os outros instrumentos de poder (p. 53). A palavra supõe um público ao qual ela se dirige como a um juiz que decide em última instância sobre diversas interpretações polêmicas. O público (o espaço político) é obrigado a decidir com base na força da palavra.

É essa escolha puramente humana que mede a força da persuasão respectiva de dois discursos, assegurando a vitória a um dos oradores sobre seu adversário. [...] Entre a política e o logos, há assim relação estreita, vínculo recíproco. A arte política é essencialmente exercício da linguagem; e o logos. Na origem, toma consciência de si mesmo, de suas regras, de sua eficácia, por intermédio de sua função política (p.54).

Essa segunda característica da polis consiste na plena publicidade dada às manifestações mais importantes da vida social. Em razão disso podese dizer que, a polis existe apenas na medida em que se distinguiu um domínio público nos dois sentidos diferentes, mas solidários do termo: um setor de interesse comum, opondo-se aos assuntos privados; práticas abertas, estabelecidas em pleno dia, opondo-se a processos secretos (p. 55).

Aos dois aspectos anteriores - prestígio da palavra e o 
desenvolvimento das práticas públicas - acrescenta-se a condição de semelhança entre os diferentes ${ }^{7}$. Tal semelhança entre iguais cria condições para a relativa hegemonia da corrente democrática.

A corrente democrática vai mais longe, define todos os cidadãos, como tais, sem consideração de fortuna, nem de virtude, como 'iguais' que têm os mesmos direitos de participar de todos os aspectos da vida pública. Tal é o ideal de isonomia, que encara a igualdade sob a forma da relação mais simples: 1/1. A única 'justa medida' suscetível de harmonizar as relações entre os cidadãos é a igualdade plena e total (VERNANT, 2002, p.103).

A representação lógica das condições de semelhança entre os diferentes tem na figura geométrica do círculo seu paradigma.

Sob a lei de isonomia, o mundo social toma a forma de um cosmos circular e centrado em que cada cidadão, por ser semelhante a todos os outros, terá que percorrer a totalidade do circuito, ocupando e cedendo sucessivamente, segundo a ordem do tempo, todas as posições simétricas que compõem o espaço cívico (p.107) ${ }^{8}$.

A materialidade da organização social escravocrata, entretanto, no processo da superação da monarquia do Rei-divino, a constituição da Polis, a hegemonia relativa da corrente democrática, as relações entre iguais entre os senhores (isonomia) desenvolveram as relações entre polis (práticas públicas) e logos (prestígio da palavra) e propiciaram a superação das formas de conhecimento atrelados à razão mítica e a doxa com o nascimento de um

\footnotetext{
${ }^{7}$ Essa semelhança cria a unidade da polis [...] só os semelhantes podem encontrar-se mutuamente unidos pela philia, associados a uma mesma comunidade... Todos os participantes do Estado vão definir-se como Hómoloi, semelhantes. (Vernant, 2002, p. 56). ${ }^{8}$ A representação lógica recorrendo à geometria é muito significativa entre os gregos. Por exemplo, o registro atribuído a Platão como condição no ingresso à Academia. "O filósofo que faz inscrever no limiar da Academia: que ninguém entre aqui se não é geômetra -, dá testemunho dos vínculos que uma mesma origem e uma orientação comum estabeleceram e mantiveram por muito tempo, entre os gregos, entre pensamento geométrico e pensamento político" (p.139).
} 
pensamento racional. Dessa forma, os fundamentos do regime da Pólis asseguram a laicização do pensamento político e o advento da episteme e da filosofia como as formas mais aprimoradas desse pensamento racional. Inaugura-se, também, os confrontos entre as diversas formas de conhecimento.

2.2. O conflito entre mito, religião (razão mítica: mythos) e o conhecimento científico (episteme)

O mito (mythos) se refere a um relato de algo fabuloso que se supõe acontecido num passado remoto e quase sempre carece de precisão, veracidade e comprovação. Os pré-socráticos consideram o mito de modo ambíguo, oposto e rechaçado pelo logos, é, ao mesmo tempo, o solo onde ele surge. Os sofistas separaram o mito da razão. Já Platão entendia o mito como um modo de expressar certas verdades (FERRATER MORA, 1999, p. 583); uma via humana mais curta para a persuasão, um produto inferior ou deformado da atividade intelectual. A ele era atribuída, no máximo "verossimilhança" enquanto a verdade pertencia os produtos genuínos do intelecto. $\mathrm{O}$ mito expressa o que é de melhor e mais verdadeiro que se pode encontrar" (Górg. 527 a), embora oposta à verdade” (Górg. 523, a).

$\mathrm{O}$ mito tem um caráter educativo no pensamento político de Platão, chamado em vários momentos da "mentira com nobreza", daquela que deve lançar mão o rei-filósofo ou o legislador-educador sempre que pretender forjar atos e comportamentos excelentes, mas que, naquele momento, a linguagem argumentativa se revela falha, ou se apresenta como o caminho mais longo a ser percorrido (Cf. SOARES, 1999, p. 233). Aristóteles assume de igual forma a mesma atitude com relação ao mito, às vezes, é oposto à verdade, mas outras vezes é a forma aproximativa e imperfeita que a verdade assume (Hist. An., VIII, 12, 497 a 7). Analogamente, atribui-se significado religioso quando designa determinadas crenças. (ABBAGNANO, 2007, p. 784).

Com relação à religião, não existe palavra grega equivalente à latina (religare), entretanto, mas pode ser entendida como crença na garantia 
sobrenatural de salvação, e técnicas destinadas a obter e conservar essa garantia (ABBAGNANO, 2007: 97). A referência grega diz respeito ao problema da origem da ligação dos homens com as divindades (EPICURO, Carta a Meneceu), entretanto, com a indiferença da divindade para com o mundo e os homens (caráter anti-religioso). Ou, pode ser entendida, segundo Critias, como um estratagema político, criado por algum homem talentoso e experiente que "inventou o temor dos deuses para que os malvados se sentissem amedrontados mesmo no que fizessem, dissessem ou pensassem às escondidas" (SEXTO EMPÍRICO, Adv. Math, IX, 54). Esse estratagema seria necessário porque as leis realmente dissuadiam os homens de praticar violências às claras, mas eles as cometiam às escondidas. Platão atribui a função da divindade como garantia de certos valores morais que regulam a ordem da vida social: divindade que, segunda tradição, rege o princípio, o fim e o curso de todos os seres, procede conforme sua natureza no seu movimento circular, atrás dela vem sempre a justiça punitiva para quem despreza a lei divina (Leis, 715 e, 716).

Tanto o mito como a religião, embora tenham uma função pedagógica, ou controladora da consciência individual, segundo a nova visão inaugurada pelo logos, são formas do conhecimento que não respondem racionalmente às necessidades e às indagações dos homens sobre os mistérios do mundo, a sociedade e sobre o próprio homem. A radicalidade do conflito entre razão mítica (mythos) e episteme (logos), exposta pelos pré-socráticos e os sofistas, é substituída pela relação de superação proposta por Platão e Aristóteles, quando aceitas como formas diferenciadas e com funções sociais diferentes do conhecimento.

\subsection{O conflito entre senso comum (doxa) e ciência (episteme)}

A Doxa (opinião) se refere a qualquer conhecimento ou crença, que não inclui garantia alguma de validade, contrapõe-se a ciência (episteme). Parmênides contrapõe as opiniões dos mortais à verdade (fragmento 1,29-30). Platão considera a opinião como algo intermediário entre o conhecimento e a ignorância (Rep. 478 c). Aristóteles afirma que ao contrário da definição e da 
demonstração, pretendida pela episteme, as opiniões estão sujeitas a mudar, portanto, não constituem ciência, mas, por outro lado, é com base em certas opiniões comuns que os homens baseiam suas demonstrações. Um exemplo disso: uma asserção pode ser afirmativa ou negativa, com base em opiniões, não pode simultaneamente ser e não ser (ABBAGNANO, 2007, p.205).

O conhecimento científico (episteme), segundo Lalande (1999), é oposto a crer ou crença, que não exigem clareza direta e intrínseca do objeto (p. 193), diferencia entre o ato subjetivo de conhecer e o fato que se refere à relação entre um objeto e um sujeito. O termo Gnosis que deu origem ao verbo gnoscere (conhecer) se refere a "qualquer procedimento que possibilite a descrição, o cálculo ou a previsão verificável de um objeto (entidade, fato, coisa, realidade ou propriedade). Diferente de crença entendida como $o$ empenho na verdade de uma noção qualquer, ainda que não aferível; o conhecimento é um procedimento de aferição ou a participação possível em tal procedimento. A doutrina do conhecimento surgiu no mundo antigo como identificação: "conhecer significa tornar o pensamento semelhante ao pensado" (Platão, Tim., 45 c, 90 c-d). O conhecimento verdadeiro só faz reproduzir o objeto. "O que é absolutamente é absolutamente cognoscível, enquanto não é de nenhum modo de nenhum modo é cognoscível. Dessa maneira, Platão estabeleceu a correspondência entre ser e ciência, que é o conhecimento verdadeiro; entre não ser e ignorância; a opinião (doxa) está entre o conhecimento e a ignorância" (Rep., 47 a). De forma mais rigorosa, para Aristóteles, o conhecimento em ato é idêntico ao objeto, caso se trate de conhecimento sensível, e é a própria forma inteligível (ou substância) do objeto, caso se trate de conhecimento inteligível (De an. II, 5, 417 a) (cf. ABBAGNANO, 2007, p.205).

\subsection{Conhecimento científico (episteme) e a filosofia (sofia)}

Para os gregos existem também diferenças e conflitos entre as duas formas mais aprimoradas do pensamento racional, embora exista uma profunda unidade entre elas como formas de superação da razão mítica e do senso comum. 
Foi Heráclito de Éfeso (544-480) quem presumivelmente criou o termo filósofo. Em grego philosophon se compõe de philos que significa amigo e sophón o fluente cordial no todo (hén panta). Filósofo, portanto, é amigo do todo, aquele que está na unidade de todos os entes (BUZZI, 1988, p. 10). Mas, é com Sócrates que a filosofia começa a empregar um método de investigação.

O método socrático, exercitado sob a forma do diálogo, consta de duas partes. Na primeira, chamada de protréptico, isto é, exortação, Sócrates convida o interlocutor a filosofar, a buscar a verdade; na segunda, chamada elénkhos, isto é, indagação, Sócrates, fazendo perguntas comentando as respostas e voltando a perguntar, caminha com o interlocutor para encontrar a definição da coisa procurada (CHAUÍ, 2002$, p.190) $)^{9}$.

Platão cria uma distinção entre o conhecimento sensível e o conhecimento inteligível. Essa distinção entre o sensível e o inteligível ou entre o visível e o invisível é a base da teoria platônica do conhecimento e da dialética como método e instrumento para passarmos da pluralidade contraditória de opiniões à unidade da ideia ou da forma (CHAUÍ, 2002, p.240). Aristóteles sintetiza sua teoria de conhecimento em duas afirmações: Todos os homens desejam por natureza saber" e "os homens começam e começaram sempre a filosofar movidos pelo espanto (tó thaumázein) [...]. Aquele que se coloca uma dificuldade e se espanta reconhecer sua própria ignorância. Por isso, o homem ama os mitos que qualificam seus espantos e a filosofia que diferentemente da ciência prática, permite manter, na forma de "silogismos dialéticos" e das "aporias" a curiosidade, o espanto e os processos investigativos perante os mistérios do mundo.

Apesar dessas nuances, para Aristóteles e para o Ocidente, até o século

\footnotetext{
9 "Diferentemente dos sofistas, Sócrates não se apresenta como professor. Pergunta, não responde. Indaga, não ensina. Não faz preleções, mas introduz o diálogo como forma da busca da verdade. Essa foi a razão de não haver escrito coisa alguma. Dizia que a escrita é muda e que sua surdez cristaliza ideias como verdades acabadas e indiscutíveis" (CHAUÍ, 2002, p.188).
} 
XIX de nossa era, filosofia e ciência eram uma só e mesma coisa. Toda ciência, diz Aristóteles, investiga os princípios, as causas e a natureza dos seres que são seu objeto de estudo. "Só há ciência quando conhecemos pelas causas" é o lema fundamental de Aristóteles (e do pensamento ocidental). No Livro I dos Segundos analíticos lemos: Consideramos que possuímos uma ciência de modo absoluto, e não de modo acidental como nos sofistas, quando julgamos conhecer a causa pela qual a coisa é, sabendo que ela é a causa disso e que é impossível que o efeito seja diferente do que ele é (CHAUÍ, 2002, p.346).

As diferenças entre as ciências se referem à natureza das coisas investigadas. [...]. Essa diferença da natureza das coisas investigadas faz com que os princípios e as causas em cada ciência sejam diferentes dos das outras e permitem classificá-los em três grandes grupos: teoréticas, cujo fim é a verdade, cujo fim é o bem humano, e produtivas ou poiéticas, cujo fim é uma obra (Id. p.346).

Aristóteles na lógica ou Órganon (conjunto dos escritos lógicos) que trata do instrumento do pensamento para pensarmos corretamente, apresenta um dos caminhos mais importantes da ciência, os analíticos, analytikós, do verbo analýo, que significa: desfazer uma trama, desembaraçar fios, desembaraçar-se de laços, dissolver para encontrar os elementos, examinar em detalhe e no pormenor, remontar às causas ou às condições. Os analíticos buscam os elementos que constituem a estrutura do pensamento e da linguagem, seus modos de operação e de relacionamentos (CHAUÍ, 2002, p.257). No mesmo Órganon distingue, dentro dos modos das linguagens, os silogismos dialéticos e os silogismos científicos. Silogismos dialéticos são aqueles cujas premissas se referem a coisas prováveis, possíveis, contingentes, verossímeis, isto, é, as coisas que podem ser ou não ser, que podem ser de uma maneira ou de outra, que podem acontecer ou não acontecer (Id. p.375). Nesse sentido, o silogismo dialético é aquele que comporta argumentações contrárias, como as dos sofistas e mesmo como as de Sócrates nos diálogos platônicos. Suas premissas são opiniões ou se referem a coisas contingentes que não são objeto de ciências, mas de 
persuasão. [...]. Aristóteles, diferentemente de Platão, não despreza a opinião, pelo contrário localiza a dóxa na dialética, embora isso signifique retirá-la do campo das ciências teoréticas" (Id. p.375). De acordo com Aristóteles $A$ ciência não é dialética porque não admite contradições, contrariedades (Id. p.375). A ciência oferece conclusões verdadeiras, já o silogismo dialético (filosófico) oferece aporias ou dúvidas objetivas inerentes ao raciocínio que está aberto a novas investigações ${ }^{10}$.

Uma vez ponderados os conflitos entre as formas de conhecimento, podemos delinear alguns desdobramentos desses conflitos na pedagogia e particularmente na formação do homem grego (Paideia).

\subsection{Paideia (por uma filosofia e epistemologia da educação)}

A Pedagogia, em sua origem, significou prática ou profissão do educador, depois passou a designar a teoria da educação. Na antiguidade clássica grega, a pedagogia era considerada parte da ética e da política e, por isso, elaborada em vista do fim que a ética e a política propunham para o homem. É o caso da Paideia. Por outro lado, a pedagogia se referia aos meios práticos utilizados na primeira educação (condução de crianças), assim parece dividida em dois ramos isolados, um de caráter teórico, o outro relativo à prática. Somente J.A. Comenius (séc. XVII) pretendeu integrá-los, elaborando um sistema pedagógico completo, fundado no princípio da pansofia (ABBAGNANO, 2007, p.871).

A Paideia grega, na sua pretensão de articular as duas dimensões teórica e prática, anuncia as bases para uma filosofia da educação na medida que se apresenta como um esforço filosófico de pensar a educação e de abordar os problemas da realidade educativa da formação do homem grego, a maneira como se constrói a humanidade desses sujeitos nas condições da construção da polis e da participação democrática dos iguais (Hómoloi), bem como de entender as estratégias para o desenvolvimento das relações entre polis (práticas públicas) e logos (prestígio da palavra) e a superação de formas

\footnotetext{
10 A aporia significa "dúvida racional e objetiva, dificuldade inerente a um raciocínio".
} (ABBAGNANO, 2007, p.87). 
de conhecimento atrelados à razão mítica e a doxa, assegurando a laicização do pensamento político. Um dos pontos chave dessa reflexão filosófica sobre a formação do homem grego se refere ao trato com o conhecimento nas formas da razão mítica, o senso comum, da ciência e da filosofia. Essas formas conflitantes se inserem no cerne da paideia. Como tratar os saberes originados nas tradições religiosas e culturais, como criar novos conhecimentos? A maiêutica socrática sintetiza uma forma pedagógica do trato com os saberes e os conhecimentos. O processo de perguntar e responder, mediado pela dúvida e o raciocínio lógico e pelo método geométrico, como já anunciamos acima. O processo de perguntar e responder se coloca no centro tanto da pedagogia como da reflexão filosófica e a análise epistemológica. As respostas tornaram-se saberes que poderão ser transmitidos, divulgados e socializados na forma de crenças ou conhecimentos ou submetidos a suspeita e à dúvida, criando a possibilidade de novas respostas. Tal centralidade da temática sobre o trato com o conhecimento no contexto de pensar uma filosofia e uma epistemologia da educação, tomando como referência, a origem da filosofia, justifica a escolha como foco central deste capítulo sobre as contribuições da filosofia clássica grega na compreensão dos problemas atuais da realidade educacional.

\section{Os principais conflitos da pesquisa em educação}

Com base nas formas clássicas do conhecimento, pretendemos a seguir destacar os principais conflitos da pesquisa em educação. Para tanto, procuramos algum eixo que permita identificar uma relação básica que constitua a unidade da produção do conhecimento. Essa relação estruturante da unidade e dos conflitos é a relação entre a pergunta e a resposta.

Tal relação apresenta-se na base do diálogo socrático. O processo que leva ao conhecimento só pode ser realizado pelo diálogo. É por meio do diálogo que o aprendiz chegaria a descobrir na sua alma o conhecimento. Nesse diálogo, Sócrates fazia o papel de animador e do filósofo que coloca as perguntas e provoca o aprendiz, levando-o a penetrar em si mesmo e descobrir as verdades (as respostas) (ANDERY, 2007, p.64). A 
complexidade do diálogo socrático e seus desdobramentos deu a base para a compreensão do conhecimento. Na modernidade Bachelard (1989), retoma essa base para apresentar uma compreensão do conhecimento. Para o espírito científico qualquer conhecimento é uma resposta a uma pergunta. Se não tem pergunta não pode ter conhecimento científico. Nada se dá tudo se constrói. (BACHELARD, 1989, p.189). Tal entendimento nos remete à relação pedagógica socrática do diálogo que consiste na relação básica entre perguntar e responder. Tal relação é medida pela lógica do método geométrico. Os resultados do processo se manifestam em saberes e conhecimentos. Vejamos a seguir essas três dimensões da fase clássica do trato com o conhecimento.

\section{O perguntar $-\mathrm{O}$ responder}

As perguntas surgem da "problematização" do mundo da necessidade. A necessidade é transformada em "problema". A essência de um problema é a necessidade, nas suas condições concretas. O domínio racional das necessidades e dos problemas exige sua transformação em perguntas. O problema ganha possibilidade de superação, quando racionalizado e traduzido em indagações, em questões e em perguntas.

As respostas para o mundo da necessidade e para os problemas, quando relacionadas diretamente com as perguntas que lhes deram origem se constituem em conhecimentos. Assim como as necessidades, os problemas e as perguntas, assim também as respostas são elaboradas em condições materiais e histórico-sociais específicas. Atender a essas condições concretas garante tanto a pertinência das perguntas como a validez das respostas. As respostas se transformam em conhecimentos e estes se organizam em sistemas de saberes que são transmitidos, disseminados, socializados e ensinados (cf. AUTOR, 2015).

\section{O método}

De acordo com a episteme grega, a relação dialógica entre perguntas e respostas, exigem alguns critérios e regras que garantem uma heurística 
maior. Esses critérios de rigor foram explicitados na forma do methodos, ou caminho. Significa que o trajeto, o roteiro ou percurso entre a pergunta e resposta devem ser justificados, revelados e explicitados. Methodos: significa o caminho do conhecimento. Dentre os caminhos possíveis, um deles ganhou destaque na fase clássica. Este método é o geométrico (o método geométrico é considerado o primeiro método epistêmico e o fundamento do método científico moderno).

O método geométrico implica um percurso duplo: sair de um ponto, chegar a outro diferente e voltar ao ponto de partida. Algumas expressões explicitam essa relação das duas dimensões do percurso: "O caminho de ida traça o caminho de volta" (Protágoras). "Aqui, somente entra o geômetra" (aviso na entrada da academia de Platão), indicando um domínio específico de raciocínio como pré-requisito ao exercício do filosofar. A compreensão da relação intrínseca entre a análise e a síntese; a dedução e a indução, entre os degraus do ascender e o descender.

A relevância do método geométrico fazia com que os antigos geômetras gregos tivessem destacada importância na comunidade dos sábios por partilharem de um método secreto de resolução de problemas, que o guardavam a sete chaves. E a eficiência de tal método já havia sido comprovada em demasia no âmbito da Geometria. Isto, aliás, fazia da Geometria um modelo de ciência que deveria ser copiado.

O duplo traçado de ida e de volta expressa a relação entre os processos da análise e da síntese. Assim, a análise é sempre seguida de uma síntese, que, de um lado, constitui uma verificação da análise, com o objetivo de assegurar que não se cometeu erro algum e, por outro lado, uma vez constatada a inexistência de erro, constitui a demonstração ou solução efetiva cuja busca motivara a realização da análise.

As respostas para o mundo da necessidade e para os problemas são elaboradas na forma de conhecimentos. As respostas são elaboradas em condições materiais e histórico-sociais concretas. Daí a sua pertinência, sua eficácia e validade histórica.

As respostas elaboradas com os critérios da episteme diferenciam-se 
das oferecidas pelo mythos e a doxa pelo imperativo do methodos. O atendimento desse imperativo exige a explicitação e a revelação da forma como se constrói a relação (o caminho) entre a pergunta e a resposta.

As respostas novas construídas, atendendo a esse imperativo do methodos, transformam-se em conhecimentos e estes se sistematizam e se divulgam na forma de saberes ou respostas já dadas.

Independentemente da forma como as respostas foram elaboradas estas podem ser classificadas em duas: em saberes e em conhecimentos. Vejamos a seguir essas diferenças.

O saber - O conhecer

O Saber é tido como conhecimento em geral ou como qualquer técnica capaz de fornecer informações obre um objeto. Mas, Grote (Exploratio philosofica, 1856, p.60) diferencia entre conhecer uma coisa, uma pessoa ou um objeto qualquer (que significa certa familiaridade com esse objeto) e saber algo ao respeito do objeto (o que significa ter dele um conhecimento talvez limitado, mas exato, de natureza intelectual ou científica). W. James aceita essa distinção em The Meaning of Trut (1909, pp. 11-12). Tal distinção é difundida por Russell (Logic and Knowlege, 1905); segundo ele, A distinção entre experiência direta (acquaintance) e conhecimento sobre (knowledge about) é a distinção entre as coisas que nos estão imediatamente presentes e as que nós alcançamos apenas por meio de frases denotativas ("on denotig"). (ABBAGNANO, 2007, p. 1022).

Se considerarmos a relação entre perguntas e respostas, essa distinção pode ser entendida como dois momentos da produção do conhecimento. Quando existe a relação direta entre o perguntar e o responder, teremos o conhecimento. Uma vez obtidas as respostas, estas ganham forma autônoma e podem ser separadas das perguntas que lhe deram origem e transformadas em informações e frases denotativas. Tais respostas poderão ser sistematizadas, organizadas na forma de informações padronizadas e selecionadas para serem divulgadas, transmitidas e consumidas em forma de dados, informações, saberes, teorias, esquemas, fórmulas, receitas, resumos, 
livros, publicações, bibliotecas e redes de informação (AUTOR, 2009, p.12). Nessa segunda fase, as respostas são deslocadas das condições concretas da sua produção e separadas da sua relação direta e dinâmica com a pergunta, transformando-se num saber (resposta já dada, já dita) pronto para ser apropriado, formatado, sistematizado, utilizado e acumulado pela humanidade. Para seu desenvolvimento posterior, precisa resgatar a sua dinâmica, através da dúvida. A dúvida transforma a resposta obtida (síntese) e afirmada como saber constituído na sua negação, na sua forma contrária (antítese), numa nova pergunta que irá exigir a produção de novas respostas.

Segundo esse entendimento da relação dialética entre perguntas e respostas, tidas como pólos opostos da mesma dinâmica, é necessário explicitar as diferenças entre conhecimento e saberes, eles se colocam de forma oposta e contraditória, no mesmo processo. Enquanto o conhecimento se refere à parte dinâmica e ao processo de qualificar perguntas e produzir as respostas novas, os saberes se referem ao produto, à resposta elaborada, passível de ser sistematizada para ser distribuída, divulgada e consumida. Nesse sentido, conhecimento e saberes, embora contrários na funcionalidade, estão juntos na dinâmica dialética entre perguntas e respostas sobre um determinado fenômeno, ou objeto.

Em síntese, podemos considerar os saberes como respostas prontas “já dadas", acumuladas e transmitidas na forma de frases denotativas, para problemas passados já resolvidos, para perguntas surgidas em outros contextos (histórico-sociais). Nesse sentido, as respostas dadas pelos saberes se distanciam das perguntas originais. Os diversos saberes acumulados pela humanidade sejam eles, míticos, opinativos, científicos, filosóficos poderão ser apropriados como saberes práticos, saberes docentes, escolares, acadêmicos, etc na relação pedagógica e nos processos de ensino. Já os conhecimentos se referem às respostas originárias e novas a serem produzidas na relação direta com as perguntas, perguntas essas que surgem de necessidades e problemas concretos para os quais não existe resposta pronta. A existência de respostas prontas ou de saberes para um determinado 
problema são indicadores de que o problema, uma vez recuperada sua resposta, deixa de ser problema, isto é, vira um falso problema ${ }^{11}$.

O verdadeiro problema não se identifica com o "não saber", ele se apresenta como obstáculo, dificuldade, conflito, dúvida, crise para o qual não se tem resposta pronta (cf. SAVIANI, 1990).

As respostas para os problemas concretos (verdadeiros problemas) não estão nos saberes. As possíveis respostas contidas nos saberes sistematizados (bibliotecas, tradições, arquivos informatizados, internet, etc.) devem ser problematizadas, submetidas a suspeita e à dúvida. Podem se transformar em ponto de partida para novas perguntas.

As perguntas complexas se originam nos problemas concretos, nas dificuldades, nos conflitos e nas crises e exigem respostas novas a serem elaboradas através da pesquisa científica e filosófica. A não existência de respostas válidas para os problemas concretos suscita novos processos de pesquisa e a produção de novos conhecimentos.

\section{Os desafios da formação do pesquisador}

Nesta parte final da exposição, pretendemos retomar o objetivo de discutir as diversas formas do conhecimento desenvolvido na antiguidade clássica grega e suas contribuições para a compreensão da problemática contemporânea da formação do pesquisador em educação. Alguns tópicos podem ajudar a focalizar esses desafios: a) como realizar as articulações entre os saberes acumulados que oferecem respostas já elaboradas e os processos de pesquisa que exigem a produção de novas respostas?; b) como superar as Pedagogias da resposta (predomínio dos saberes) e incentivar a formação do pesquisador com as Pedagogias da pergunta (pesquisa)?

Com base na diferença entre os saberes e o conhecimento, podemos diferenciar também os protocolos do ensino e da pesquisa. No entendimento de que os saberes e os conhecimentos são respostas a perguntas que surgem

\footnotetext{
${ }^{11}$ Quando o problema tem resposta vira falso problema (pseudoproblema). Nesse sentido, a existência de saberes que respondem ao problema, falseia esse problema. Será falso problema, porque já tem resposta para ele. O problema está em não saber essa resposta.
} 
no mundo da necessidade e da problematização dessas necessidades históricas e concretas da humanidade e de cada sociedade, o pesquisador deverá se apropriar desses saberes, mesmo que sejam respostas "já dadas", "prontas" e limitadas a contextos geográficos e históricos diferentes. Muitas dessas respostas, particularmente as mais significativas e relevantes, já foram fixadas e/ou organizadas em sistemas de informação e disseminadas nos sistemas escolares, e, se constituindo como base das denominadas "Pedagogias das respostas".

Mas, quando esses saberes são submetidos ao crivo da dúvida e da suspeita sobre sua validade e pertinência para responderem às necessidades $\mathrm{e}$ problemas concretos que a realidade apresenta, nas condições específicas de uma dada sociedade e do desenvolvimento científico e tecnológico, surge então a necessidade da produção de novas respostas, seguindo os protocolos próprios da pesquisa científica e filosófica. Neste caso, falamos, então, de uma outra pedagogia que dá prioridade à indagação, à suspeita, à dúvida e desenvolve os domínios e as exigências da pesquisa científica. Trata-se então das Pedagogias da pergunta.

O debate entre os saberes e o conhecimento e entre as pedagogias da reposta e da pergunta é oportuno na fase atual da "pós-verdade" e do “capitalismo cognitivo". De acordo com Duarte (2003), que já prenuncia essa fase, quando elabora a crítica à "falsa sociedade do conhecimento" e à nova escola nova, essa falsa sociedade do conhecimento, que tem suas bases nas pedagogias da competência, do aprender a aprender, do construtivismo e na linha do professor reflexivo, subestimam a transmissão dos saberes e as experiências acumuladas e privilegiam as aprendizagens que o indivíduo realiza por si mesmo (escola nova). "É mais importante o aluno desenvolver um método de aquisição, elaboração, descoberta, construção de conhecimentos que esse aluno aprender os conhecimentos que foram descobertos por outras pessoas" (cf. 2003, p.8). Com base nos postulados da escola nova, a aprendizagem deve ser impulsionada e dirigida pelos interesses da própria criança e visa preparar os indivíduos para acompanhar a sociedade 
no seu acelerado processo de mudança, em que os conhecimentos já elaborados se tornam caducos e provisórios em forma rápida.

No ambiente das novas tendências do neopragmatismo, associado ao novo escolanovismo, anuncia-se um desprezo pelos saberes clássicos e se consolida um praticismo imediatista em que a teoria perde importância e recua a espaços restritos dentro das escolas e as faculdades onde se formam os docentes e os pesquisadores. Tais desprezos e recuos parecem caracterizar os postulados das reformas educativas que de forma soterrada pretendem a “uberização da educação". Segundo (SCHEIBE, 2007), a definição da prática da docência apenas como a base da formação do educador e do domínio de técnicas e das formas de acesso às informações, também como a base da formação do pesquisador, são expressões da "epistemologia da prática”. Decorre daí o desafio para uma formação articulada com a teoria.

O desafio é estabelecer uma formação teórica sólida, com base no conhecimento científico e na pesquisa consolidada, e não ceder à incorporação da racionalidade técnica ou do praticismo pedagógico predominante na epistemologia da reforma educacional oficial, na qual se vincula o conhecimento formativo a uma prática imediatista (p.60).

Nesse sentido, o propósito deste capítulo, de resgatar a problemática clássica do conhecimento e o confronto entre as diversas modalidades, é uma forma de trazer esses elementos teóricos para compreender os atuais desafios da formação do pesquisador.

\section{Conclusões}

À guisa de conclusões, cabe apontar a necessidade de defender algumas estratégias de articulação entre a apropriação dos saberes acumulados e os desafios da construção das respostas novas, entre os processos de ensino e de pesquisa já anunciadas no debate entre as pedagogias da resposta e as pedagogias da pergunta e da problematização.

1. Apropriação e disseminação dos saberes acumulados pela humanidade e, com base no seu domínio, desenvolver novos conhecimentos; 
2. Incentivo à curiosidade, à suspeita, à dúvida, à indagação, às questões e às perguntas, problematizando as respostas produzidas pelas diversas formas do conhecimento (mythos, doxa, episteme, filosofia);

3. Qualificação permanente das perguntas e das pedagogias que incentivam a construção de perguntas e a problematização permanentes dos saberes.

Essas estratégias, apontadas a partir do debate sobre as formas do conhecimento na filosofia clássica grega e das polêmicas entre as pedagogias e suas propostas sobre o trato com as formas básica da produção e difusão do conhecimento acumulado pela humanidade (relação pergunta-resposta), certamente poderão ajudar no resgate da problematização dos saberes científicos, acadêmicos e escolares e da necessidade de inserir a capacitação básica para a pesquisa e a produção do conhecimento na formação e na prática profissional dos educadores, sem recuar e negar os saberes acumulados pela humanidade.

Entretanto, não podemos concluir sem apresentar, à semelhança da filosofia grega, algumas aporias ${ }^{12}$.

A aporia básica consiste em definir as estratégias de articular, na formação do pesquisador em educação, as reflexões oriundas da prática filosófica de pensar a educação ou do desenvolvimento da "reflexão de forma radical, rigorosa e de conjunto sobre os problemas que a realidade educacional apresenta" (cf. SAVIANI, 1986, p.29). Como integrar a reflexão filosófica sobre a formação humana na prática pedagógica? Como integrar as respostas elaboradas historicamente sobre os problemas da educação do homem? Como considerar elaborações clássicas, como as aqui apresentadas sobre os conflitos entre as formas do conhecimento na formação do educador e na prática pedagógica nas condições históricas da atual sociedade brasileira? Essas suspeitas e indagações gerais podem ser desdobradas nas seguintes aporias específicas:

1. O homem é um ser natural, isto é, faz parte da natureza, mas ao mesmo tempo, diferencia-se da natureza, por "um corpo inorgânico do homem"

\footnotetext{
${ }^{12}$ Aporias referem-se a dúvidas geradoras de novas buscas. Aporia significa "dúvida racional e objetiva, dificuldade inerente a um raciocínio” (ABBAGNANO, 2007, p.87).
} 
(MARX, 1984, p.111) que corresponde às experiências e conhecimentos produzidos e transmitidos de geração a geração através da educação e a cultura. A interação homem-natureza é um processo permanente de mútua transformação: esse é o processo de produção da existência humana. É o processo da produção da existência humana porque o homem não só cria artefatos, instrumentos, como também desenvolve ideias e conhecimentos, fruto da interação homem - natureza que redundam na produção da sua própria existência. $\mathrm{O}$ processo de produção da existência humana é um processo social. Na base desse processo social, está o trabalho que gera as condições de sobrevivências e os conhecimentos necessários para seu desenvolvimento. O conhecimento humano, em suas diferentes formas (senso comum, científico, teológico, filosófico, estético, etc.), exprime as respostas que o homem elabora para suas necessidades, seus problemas e suas indagações e perguntas. Como considerar essas reflexões acumuladas na formação do educador e na sua prática pedagógica?

2. O conhecimento acumulado e sistematizado na forma de saberes pode ser objeto de processos pedagógicos (pedagogias das perguntas e pedagogias das respostas). As contradições expostas entre os saberes escolares e o conhecimento, entre as pedagogias da resposta e das perguntas, possibilitam a superação dos limites e dificuldades dos conteúdos impostos pelas diversas pedagogias. Como integrar essa distinção entre saberes e conhecimentos e resgatar a contribuição do debate da problematização dos saberes apresentados nas escolas com a necessidade de inserir a pesquisa e a produção do conhecimento, tanto na formação do educador como na sua prática pedagógica?

3. Como equacionar na formação profissional dos educadores, as demandas da dinâmica de acumulação de saberes e os critérios de rigor científico que exige a produção de novos conhecimentos? Como atender a necessidade de domínio de saberes cada dia mais abundantes, dispostos nas linhas de consumo e nas redes de informação, e a qualificação crítica desses saberes, na hora de encontrar respostas válidas para os problemas 
e necessidades da prática social do educador e de cumprir com seus compromissos históricos de potencializar a sociedade do futuro?

4. Como desenvolver novas capacidades no educador para articular o domínio dos saberes sistematizados e o potencial criativo da pesquisa científica e dos instrumentais técnicos e teóricos, necessários para a produção de novas respostas para as necessidades históricas da sociedade na fase atual de profundos processos de transformação?

\section{Referências}

ABBAGnANO, N. Dicionário de Filosofia. São Paulo: Martins Fontes, 2007.

ANDERY, M. A. et al. Para compreender as ciências: uma retrospectiva histórica. Rio de Janeiro: Garamond. 2007.

ANPED, CNPq. Avaliação e perspectivas na área da educação, 1982-1991. Porto Alegre: CNPq., 1992.

BACHELARD, G. Epistemologia. Barcelona: Anagrama, 1989.

BUZZI. A. Introducão ao pensar. o ser, o conhecimento, a linguagem. Petrópolis: Vozes, 1988.

CHAUÍ, M. Introdução à história da filosofia: dos pré-socráticos a Aristóteles, v. I. 2. ed., rev. e ampl. São Paulo: Companhia das Letras, 2002.

DUARTE, N. Sociedade do conhecimento on Sociedade das ilusões? Campinas, SP: Autores Associados, 2003.

FERRATER MORA, J. Diccionario de Filosofía de Bolsillo 2. Madri: Alianza Editorial, 1999.

FERREIRA, W. R. V. "Uberização" da educação: saem pedagogos e Construtivismo, entram gestores e neurociências. Cinegnose, 20 de abril de 2017. Disponível em: https://cinegnose.blogspot.com.br/2017/04/uberizacao-daeducacao-saem-pedagogos-e.html\#more

FREIRE, P.; FAUNDEZ, A. Por uma pedagogia da pergunta. Rio de Janeiro: Paz e Terra, 1985.

JAEGER, W. Paideia: a formação do homem grego, São Paulo: Martins Fontes, 2001.

MANACORDA, M. História da Educação: da antiguidade a nossos dias. São 
Paulo: Cortez, 1989.

MARX, K. O Capital. Livro I, Volume I. Rio de Janeiro: Civilização Brasileira, 1968.

MOROZOV. E. Wall Street e Vale do Silício juntos. Resistir à Uberização do mundo. Le Monde Diplomatic, 4 de novembro de 2015, Disponível em: http://diplomatique.org.br/resistir-a-uberizacao-do-mundo/. Acesso em 21/04/2017.

SAVIANI, D. A pedagogia no Brasil: História e Pedagogia Campinas, SP: Autores Associados, 2008. - Educação: do Senso Comum à Consciência Filosófica. São Paulo: Autores Associados: Cortez, 1990. . Escola e democracia. São Paulo: Autores Associados, 1986.

SCHMIED-KOWARZIK. Pedagogia Dialética. São Paulo: Brasiliense, 1983.

SOARES, A. J. Dialética, Educação e política: uma releitura de Platão. São Paulo: Cortez, 1999.

SUCHODOLSKI, B. A pedagogia e as grandes correntes filosóficas: pedagogia da essência e da existência. Lisboa: Livros horizonte, 1978.

VERNANT, J.-P. As origens do pensamento grego. 12. ed. Rio de Janeiro: Difel, 2002. VILLAS-BÔAS, M. A. Pós-verdade: o conceito político da moda é equivocado. Carta Capital, 16 de abril de 2017. Disponível em. https://www.cartacapital.com.br/blogs/vanguardas-do-conhecimento/oconceito-politico-da-moda-pos-verdade-e-equivocado, acesso 22/04/2017 WARDE, M. A. produção discente dos programas de pós-graduação em educação no Brasil (1982-1991): avaliação e perspectivas. In: ANPED. Avaliação e perspectivas na área da educaşão, 1982-91. Porto Alegre: CNPq, 1993. p.51-82. 